\title{
Components of the Digital State Financial Control System in the Russian Federation
}

\author{
Gordienko M.S.
}

\author{
Plekhanov Russian University of Economics, Moscow, Russia \\ E-mail: gordienkomikhail@yandex.ru
}

\begin{abstract}
The article is dedicated to the consideration of the main components of the digital state financial control system in the Russian Federation, used in the management of socio-economic systems. The following system components are classified and described: automated identification tools, remote control devices, as well as automatic analysis information systems, with appropriate subsystems of automated remote control devices and non-automated remote control devices, including personalized and non-personalized automatic control devices. For each component of the system, an example of a specific practical implementation (labeling, ACK VAT, tax monitoring, etc.) is given, an assessment of the financial and economic effect of the application of various forms and types of control is given. The positive and negative effects of the introduction of the analyzed components of the control system are indicated, which are presented in the conclusions to this publication.
\end{abstract}

Keywords: economy, Russia, digital technologies, digital control, state control, financial control, taxation

\section{INTRODUCTION}

In 2018, the passport of the national program "Digital Economy of the Russian Federation" was approved, in accordance with which it is planned to carry out digitalization of all spheres of economic activity of the Russian Federation till 2024. The set task concerns (including) the subjects of control and supervisory activity, which must comply with the competency, methodological and technological level to the objects of control. Today, this compliance is not always fulfilled, therefore it is worth considering the main components, that can be implemented in the general system of digital state control in order to increase its effectiveness, including the financial component.

The category of "digital state control" can be understood in a broad sense as: planning, conducting and processing the results of control measures in electronic form within the framework of departmental record management; the regulator conducts inspections on the Internet, including the collection of data about controlled persons; analysis of the collected data with the identification of information about potential violations or the identification of facts of specific violations.

\section{METHODS OF RESEARCH}

The article analyzes data from open sources with a description of existing forms of state digital control. This allows to create a review of organizational and technical solutions, used to create specific tools for innovative control, as well as to carry out their functional comparison, the degree of applicability and effectiveness in the management of socio-economic systems.

When preparing the article, such methods were used as: systemic, ontological, epistemological, synergetic, historical, logical, analytical, as well as statistical. Among the key ones, used to analyze the problem field, the principle should be noted: adequate reflection, conscious reflection; complexity; consistency; problematization; communication and development and others.

\section{RESEARCH RESULTS}

\subsection{Automated identification tools}

Automated identification means - designed to store data in a machine-readable format and provide automated processing of information by reading it (for example, barcode, radio frequency identification, etc.). The identification algorithm is shown in figure 1 .

The mandatory labeling of fur products by agreement of the Member States of the Eurasian Economic Union (EAEU), which entered into force in 2016, should be given as example. 
The manufacturer applies a digital code (marking) in the form of a 2D DataMatrix barcode or RFID tags (Radio Frequency IDentification, Radio Frequency Identification).

The goods are transported to the point of sale, while the movement of goods can be tracked in the electronic document management system (EDF).

At the place of arrival, the goods are scanned, after which it becomes available for sale.

As soon as the goods are bought, the code leaves the "turnover". Data is transmitted via electronic checks from online cash registers.

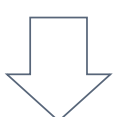
The consumer has verified data on the product, which he receives from the
accompanying information on the product itself (packaging, label) or in the mobile application.

Figure 1 The labeling algorithm for certain categories of goods in the Russian Federation

The Federal Tax Service of the Russian Federation became the responsible authority for the implementation of this area, the issue of marking was assigned to LC "Goznak". The financial and economic effectiveness of this approach is confirmed by data on the import of fur products, which already in 2017 began to be adjusted upwards. For example, the weight of imported goods grew by $66 \%$, and customs payments by $80 \%$. In 2018 , the system continued to scale, total indicators amounted to 2.2 million of imported units of fur products worth more than 130 billion rubles. Despite the fact, that there are still no final indicators for the past year, it is possible to note confidently the fact, that the system allowed to significantly vindicate the controlled sphere.

The effect of the introduction of this component is, that it: prevents the illegal import and unofficial domestic production of this type of goods under the guise of other, less marginal (which was carried out for the purpose of tax and customs optimization); allows to establish the manufacturer of the goods in case of harm to the health of the consumer.

\subsection{Automated and non-automated remote control devices}

Remote control devices - designed for remote data exchange, monitoring and state monitoring of various kinds of indicators, as well as for the formation of managering and controlling commands for subsystems. Remote control devices in automation systems are divided into non-automated and automated.
Non-automated remote control devices - designed to conduct remote monitoring of the activity of the control object without mandatory automatic inspection of compliance with mandatory requirements. The remote sensing or photographing of the earth's surface in order to inspect objects under construction or constructed, their further administration and systematization of land relations in the Russian Federation should be given as example. Photographic materials, obtained with the use of aircraft and spacecraft, are analyzed by the staff of the Unified State Register of Real Estate. If necessary, employees carry out an additional inspection - both cameral and onsite, without crossing the boundaries of the analyzed area, if it is fenced off.

The effect from the implementation of this component is, that it can significantly reduce the number of on-site inspections, which minimizes the time costs of employees and allows to increase the number of inspections. At the same time, until effective image analysis algorithms have been developed - all the analytical work on comparing the images is carried out by an employee, which means, that labor productivity is much lower compared to machine processing, and a human factor also appears.

Automated remote control devices - designed to automatically measure and record indicators of controlled activity and transfer data to relevant information systems. These control devices can be classified into:

- personalized automatic control devices - designed to control the activities of specific objects;

- non-personalized automatic control devices - designed to control an indefinite range of objects.

The implemented approach of tax monitoring, in which the economic entity provides access to its automated accounting system in real time mode should be given as 
example. The advantage of applying this approach is, that the economic entity, in case of doubt about the correctness of accounting and fulfillment of its obligations to the state, can request a motivated opinion on this issue from the tax authority. Thus, the approach is aimed at minimizing the punitive component and maximizing the consultating one. The effect from the implementation of this component is that it allows to constantly control the financial parameters of the economic entity as a whole, reducing the likelihood of various kinds of inspections, however, the negative point is the need to bear the costs on technological equipment, as well as the risk of data leakage, that constitute a commercial secret, when transferred to the control authority information system.

\subsection{Automated analysis information systems}

Automatic analysis information systems - designed to collect and analyze data on controlled objects, obtained from sensors, or provided by the controlled objects themselves to identify the prerequisites for potential violations, as well as to identify violations themselves or to collect data on already occurred violations.

The most striking instance is the automated system for monitoring the reimbursement of value added tax (ASK VAT), introduced into the practice of the Federal Tax Service of the Russian Federation. The system automatically compares data on received and issued invoices of counterparties, builds chains of goods, and also identifies tax gaps. In addition, the accumulated information on conducted transactions allows the system to asses a particular economic entity from the point of view of tax risk according to the classical three-level scale, which is further used during tax inspections.

In 2008-2017, the number of on-site inspections by the Federal Tax Service of the Russian Federation decreased from 87.9 to 20.2 thousand; in 2018, average, only 2 out of 1000 economic entities were being inspected on an on-site basis. In a small business group, one out of 4,000 taxpayers is inspected. Intake from one inspection increased by $30 \%$ compared to the previous period up to 10-12 million rubles. For the five months of 2019, the administrative load on the business continued to decline. In the first quarter of 2019, the number of on-site tax inspections decreased by $36 \%$ and amounted to 2.7 thousand, the total intake from on-site inspections increased by $10 \%$ in total and brought 48 billion rubles to the budget of the country. Thanks to ASK VAT, for three months of 2019, taxpayers voluntarily specified their obligations in the amount of almost 29 billion rubles with an increase of 2.4 times. The use of ASK VAT, as well as some other hardware and software, allows the tax service as a whole to remotely determine risk zones, conduct detailed pre-inspection analysis and go out with inspection only in exceptional cases.

A flexible approach to the selection of specific components, their combination and improvement will allow to increase the overall effectiveness of the system of digital state financial control in our country.

\section{DISCUSSING THE RESULTS}

Distinguish and present in the results of the study the main components of the digital control system, presented in figure 2 .

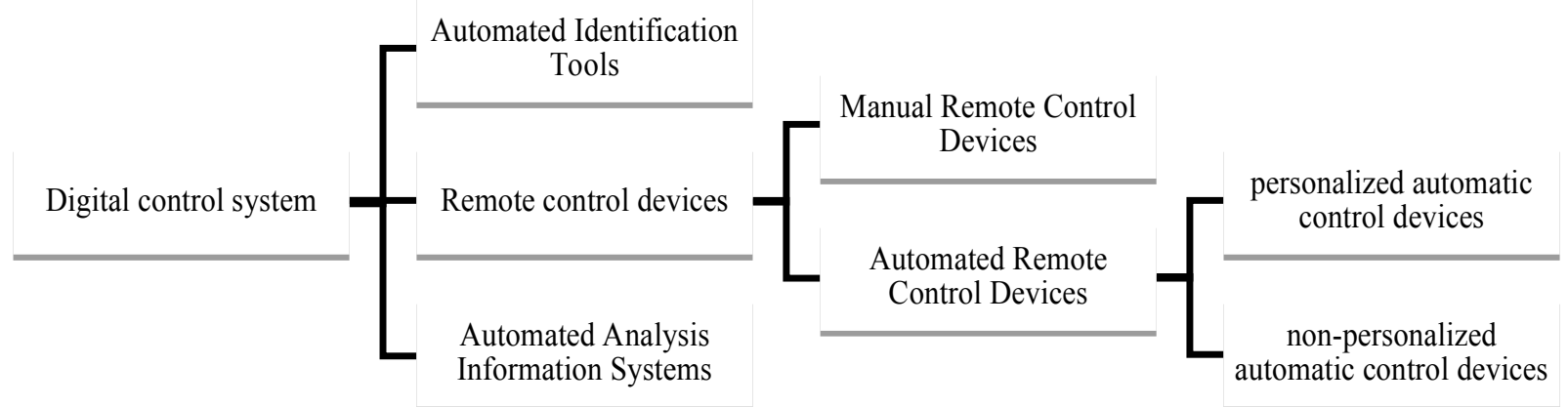

Figure 2 Components of the digital state financial control system in the Russian Federation

As we see from the figure, the digital control system includes three basic components, one of which is divided into component elements.

The first component of digital control - automated identification tools allow to keep a piece count of the most fiscally important items to ensure the highest level of traceability: alcohol, fur products and other goods. The use of these tools allows to:
- more effective prevent illegal importation (usually under the guise of cheaper goods) or illegal production within the country;

- more effective establish liability by the source of origin of a given product, which ultimately raises the quality and production standards.

These measures are useful from the point of view of legalizing the state's economy, as they reduce the possibility of unauthorized use of trademarks and force out from the market entities, that benefit from non-compliance with mandatory requirements. Altogether, this allows to 
increase the competition and quality of goods in the market. The fiscal interest of the state is to stimulate the payment of taxes and fees, as well as to increase the effectiveness of control measures: examinations, certifications, quality compliance and others.

The difficulty in introducing this technology is the need to equip all units of products with automated identification tools, and it is possible to inspect the availability of these tools only by inspecting individual batches. This kind of control laid also on the public - the consumer of the goods, who can inspect and report the absence of labeling of the goods. However, not every consumer will be able and willing to engage in this activity, in addition, not everyone has the corresponding competencies of their rights, and someone may be consciously interested in acquiring illegal goods due to lower prices. That is why the need for conducting control activities with the participation of officials - conducting on-site inspections and test purchases remains.

Video control and remote sensing systems are intermediate between the traditional form of conducting on-site inspections and automated remote measurement of the parameters of controlled activities. Such tools can reduce the number of on-site inspections, optimize time costs, increase the number of inspected objects per time unit. The latter fact, in this case, does not lead to a proportional increase in the administrative costs of the controlled person for conducting inspections. The use of such remote tools of control does not require the presence of representatives of the inspected economic entity to accompany the inspector and provide documents. However, in the control system, the main decision-maker subject is a person who, when examining the objects and comparing the received graphic image of the inspected object (courtyards, network of streets, constructed and reconstructed capital construction object, land) with the requirements, established by the normative and legal acts, makes any decision. This fact allows us to conclude, that information processing is slower and has a greater probability of error, than automated analysis.

Personalized control devices allow to continuously obtain the parameters of controlled moving and stationary objects. Indicators are generated automatically, without human participation, so they are more reliable. If there is protection against unauthorized adjustment of settings and data, objectivity of measurement and fixation is achieved, which eliminates abuse by not only economic entities, but also inspectors. The possibility to automatically record the parameters of controlled objects and remote data transfer to the controller allows to reduce the need for on-sire inspection (eliminates the need to spend time, traveling to the location of the controlled person or object, creates the opportunity to work in the usual personal office of a departmental information system), as well as reduce the costs of inspectors the control authority and the inspected entities themselves (eliminates the need to bear the costs on escorting inspectors at the facility, on submission of documents). A negative point, contributing to an increase in the quasi-fiscal load on the business, is that the mandatory installation and maintenance of such devices, as well as the communication channel for transmitting data to control authorities, is usually carried out at the enterprises own expense.

Automatic devices for controlling an indefinite circle of persons are convenient, since:

- $\quad$ allow to make objective and constant measurement of parameters of controlled objects with remote transmission of information in real time to departmental information systems to decide on the imposition of penalties for violations. Such an approach allows to reduce the costs of the control authority and controlled persons for conducting on-site control, as well as minimizes the likelihood of abuse of inspectors and economic entities;

- $\quad$ installation and maintenance are carried out at the expense of control authority, while the Controlled persons bear neither financial nor time expenses for the organization and implementation of control.

The disadvantage of automatic devices for controlling an indefinite circle of persons is the limited use, because the technology is focused on the control of moving objects vehicles, which are easily identified by the state registration plate.

And finally, profile specialized information systems are aimed at automatic analysis of compliance with mandatory requirements. Systems provide extremely high performance. This is evidenced by the above data on an increase in the collection of VAT when reducing the volume of tax gaps (see figure 3), reducing the number of on-site tax inspections when intake is increased, reducing the average time for customs operations as a result of switching to automatic mode. 


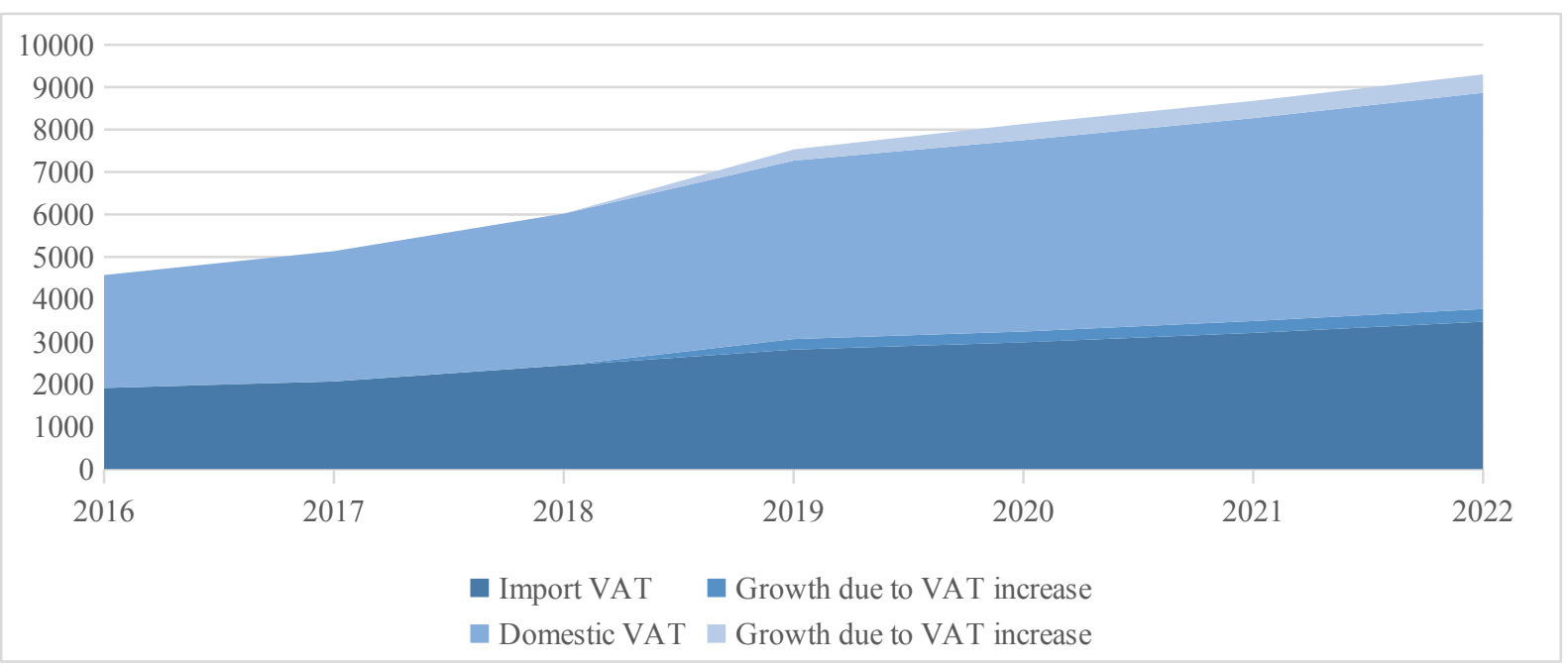

Figure 3 Dynamics of VAT intake in 2016-2022, fact and predict in billion rubles.

The use of information systems and automatic analysis by control authorities has ambiguous consequences for the business community. On the one hand, the use of effective inspection algorithms, combined with the high performance of modern information systems, allow to reduce the number of on-site inspections and the duration of control procedures. On the other hand, these information systems allow to significantly increase the depth of control, which means an increase in the likelihood of detecting both intentional and unintentional violations. To prevent such violations, economic entities must bear additional costs for consulting or use various new formats of interaction with controlling entities.

\section{CONCLUSION}

Having considered the main types of digital control technologies, summarize and list the advantages and disadvantages of each of them.

1. Automated identification tools

- advantages: effective counteraction to illegal production, import and turnover of goods; in case of harm - a simplified determination of the source of origin and suppression of the spread of dangerous goods; tracking the chain of movement of goods from producer to consumer;

- disadvantages: continued need for on-site inspections and test purchases to prevent the spread of unlabeled goods; control over the production of the identifiers themselves.

2. Non-automated remote control devices:
- advantages: a multiple increase in the intensity of control and the number of inspections in the absence of costs of the inspected persons for the inspection support; creation and storage of a database of inspected objects, allowing to track the chronology of changes in the parameters of the controled object; the human factor in the analysis procedures allows to identify nonstandard, unnoticable violations from the point of algorithm;

- disadvantages: the analysis does not exclude the human factor - less accurate compared to machine analysis, but with lower performance and a higher probability of error.

3. Personalized automatic control devices:

- $\quad$ advantages: the possibility of objective and permanent fixation of the controlled parameters of production facilities; reducing the need for onsite control, which helps to reduce the costs of the control authority and inspected entities;

- disadvantages: bearing costs for installation and maintenance of devices by controlled persons, which creates an additional quasi-fiscal load on the business; the need to install multiple devices with similar functionality on one object; violation of the rights and freedoms of controlled objects with violation of the integrity of control data, their leakage.

4. Automatic devices for controlling an indefinite circle of persons:

- $\quad$ advantages: the possibility of objective and permanent fixation of the controlled parameters of production facilities; reducing the need for on- 
site control, which helps to reduce the costs of the control body and audited entities; the imposition of costs on control authorities;

- disadvantages: limited scope of application of this digital control tool (at present - only in the field of vehicles); violation of the rights and freedoms of controlled objects with violation of the integrity of control data, their leakage.

5. Automated analysis information systems:

- advantages: reducing the number of on-site inspections and the duration of control procedures;

- disadvantages: additional costs of controlled persons in connection with the expansion of the capabilities of the control authority to detect violations.

The final choice of this or that form of control will depend on the goals and objectives of the controlling authority, its financial capabilities, as well as on the current regulatory legal field, that determines the role and liability of the parties in the process of controling and managing social and economic systems.

\section{REFERENCES}

[1] Control and supervisory and licensing activities in the Russian Federation. Analytical report 2018. RSPP and HSE.

[2] Gryzunova, N.V., Pyatanova, V.I., Manuylenko, V.V., Ordov, K.V. Models of credit limit-setting for companies as a means of encouraging competitiveness. Volume 7, Issue 1, 30 September 2019, Pages 615-625.

[3] Gryzunova, N., Shuvalova, E., Polyakova, A., Kerimov, K. Competitive capacity of companies as a major goal of national monetary policy in the context of financial globalization. Volume 12, Issue 6, Fall 2017, Pages 1585-1592.

[4] Valentey S. Counterinnovative environment of the Russian economy. Voprosy Ekonomiki. Volume 2005, Issue 10, 2005, Pages 132-143

[5] Ponomareva N.V., Zvereva A.O., Golubtsova E.V., Ilyashenko S.B. Tax incentives for use of alternative energy sources in the Russian Federation. International Journal of Energy Economics and Policy. 2019. 9(4), Pp. 144-148.

[6] Nigamaev A.Z., Gapsalamov, A.R., Akhmetshin E.M., Prodanova N.A., Savchenkova D.V.
Transformation of the tax system during the middle ages: The case of Russia. European Research Studies Journal. 2018. 21(3), Pp. 242-253.

[7] Vandina O., Mkrtychan Z., Denisov I., Vechkinzova Y. The tax mechanism of managing the process of formation of information economy in modern Russia. Entrepreneurship and Sustainability Issues. 2018, 6(2), Pp. 830-839.

[8] Pozdnyakova, U.A., Bogoviz, A.V., Lobova, S.V., Ragulina, J.V., Popova, E.V. The mechanism of tax stimulation of industry 4.0 in modern Russia. Studies in Systems, Decision and Control. 2019, 182, Pp. 189197.

[9] Valentey S.D., Bakhtizin A.R., Bukhvald Ye.M., Kolchugina A.V. Development trends of the Russian regions. Economy of Region. Issue 3, 2014, Pp. 9-22.

[10] Kazakova, N., Shuvalova, E., Chemarina, A., (...), Kurochkina, I., Sokolova, E. The mechanism for creating an effective international strategic alliance in the field of air transportation. Volume 68, 2019, Pages 704-713.

[11] Kookueva, V.V., Tsertseil, J.S. Formation of innovation clusters as a basis for the development strategy of Russia's territories. Volume 8, Issue 9, September 2019, Pages 1728-1732

[12] Kolmakov, V., Ekimova, K., Ordov, K., Aliev, A., Tchuykova, N. Monetary policy influence on companies' competitiveness through credit channel. European Research Studies Journal. Volume 21, 2018, Pp. 614-623.

[13] Shuvalova, E., Sibatulina, N. Influence of tax policy on environmental processes of resource saving. Volume 18, Issue 1.5, 2018, Pages 125-132.

[14] Romanchenko O., Shemetkova O., Piatanova V., Kornienko D. Approach of estimation of the fair value of assets on a cryptocurrency market. Advances in Intelligent Systems and Computing. 2019. T. 850. Pp. 245-253.

[15] Borodin, A., Shash, N., Panaedova, G., Kairbekuly, A., Mityushina, I. The impact of the publication of non-financial statements on the financial performance of companies with the identification of intersectoral features. Volume 7, Issue 2, December 2019, Pages 1666-1685. 